Print ISSN: 2234-3040 / Online ISSN 2234-3059

doi:10.13106/eajbm.2018.vol8.no3.33

\title{
The Effects of Chinese Consumers' Self-Construal and Advertising Type on Brand Attitude*
}

\author{
Nak-Hwan Choi**, Huan $\mathrm{Liu}^{* * *}$, Zhonghua $\mathrm{Li}^{* * * *}$ \\ Received: June 16, 2018. Revised: June 22, 2018. Accepted: July 15, 2018.
}

\section{Abstract}

Purpose - This study focused on the attitude differences towards harmony-focused Ad and uniqueness-focused Ad, also those towards brand advertised in each of the two type Ads between self-construals.

Research design, data, and methodology - Main survey was conducted online with the people in China, and collected 107 data through harmony Ad questionnaire and 109 data through uniqueness Ad questionnaire. Anova and t-test were used to verify hypotheses.

Results - First, More positive attitude towards harmony-focused Ad and the brand in it there was at interdependent Chinese consumers than at independent Chinese consumers. Second, the independent Chinese consumers and the interdependent Chinese consumers did not form significant attitude difference towards uniqueness-focused Ad. However the independent Chinese consumers showed more positive attitude towards the brand in the uniqueness-focused Ad than the interdependent Chinese consumers.

Conclusions - By highlighting the attributes of Chinese consumers' self-construal, to appeal to interdependent Chinese consumers, marketers should develop harmony-focused advertisement, and they should appeal to independent Chinese consumers by using uniqueness-focused advertisement. However the harmony might be pursued as the main content in the overall environment by Chinese people. Therefore it is necessary for the marketers to consider the harmony even when appealing them by emphasizing the uniqueness.

Keywords: Collectivism, Harmony Ad, Individualism, Self-Constural, Uniqueness Ad.

JEL Classifications: C83, L81, M31, P46.

\section{Introduction}

China had seemed as the typical collectivistic country. Singh, Huang, and Thompson(1962) found that Chinese scored the highest on the need for society-centered orientation. Chinese understand their personal identity as one's place within group of the society. In China traditional culture, harmony is a reflection of cultural values of building and maintaining the relations between individual and group

* This research was supported by "Research Base Construction Fund Support Program" funded by Chonbuk National University in 2018.

** First Author, Professor, Department of Business Administration, Chonbuk National University, Korea. E-mail: cnh@jbnu.ac.kr

*** Co-Author, Master, Chonbuk National University, Jeonju, Korea. E-mail: 1215782516@qq.com

**** Corresponding Author, Doctoral Student, Chonbuk National University, Korea.

Tel: +82-63-270-2998, E-mail: karry9211314@naver.com or social environment, and following social norms plays role as a critical goal of maintaining group harmony(Yang, 1981). The most important and the first of the traditional cultural values is harmony. In modern Chinese society, harmony is still an important value concept pursued by the Chinese people.

Ho and Chiu(1994) claimed that individualism focuses on value of self-autonomy and pursuing self-sucess and self-uniqueness. Contrary to harmony from collectivism, individualism emphasizes uniqueness. Uniqueness simply means being different from others, but there are many different ways in which individuals can keep self-uniqueness, for example, such as pursuing their own success or being autonomous and independent from others.

The value differences between individualism and collectivism reflect the relationship between society and individual(Kim, 1994). When discussing the relationship, independent self and interdependent self are distinguished from each other (Markus \& Kitayama, 1991). Collectivism helps people attach great importance to cooperation, supporting each other, and 
maintaining a harmonious social relationship. On the contrary, individualistic culture advocates independent self, which emphasizes independence, individual uniqueness and personal achievement or success.

In the other hand, after Deng Xiaoping's speech to Southern China in 1992, in order to stimulate consumption Chinese government had encouraged individual hedonism $(\mathrm{Ci}$, 1994). Regardless of changes in policies, Chinese dominant ideology has directed toward consumerism and consumer culture(Zhao \& Belk, 2008). Moreover, the Third Plenary Session of the 18th Central Committee of the Communist Party of China at 2013 stressed the importance of economic system to reform Chinese consumption ideology. The plenum suggested the decisive role of market in allocating resources and emphasized the necessity of the market economic system of enjoying independent management and fair competition, consumers' free choice to speed up the improvement of a modern market system. China is recognized as one of the fastest economically growing countries in the world, with its annual GDP growing by an average of nearly 10 percent by year of 2013(Morrison, 2014). Nowadays, great economic changes have taken place in China(Lee \& Wang, 2018). the impact of economic development has been accompanied by changes in cultural values. Hofstede(1980) presented that with economic development individualism will be highlighted. With the development of China's market economy, the cultural value of Chinese society begins to be gradually changed toward individualism and there are values directed toward personal consumption action. The cultural change will bring about great market changes.

Increasing economic and purchasing power could give rise to needs of more independence and less interdependence (Emery \& Tian, 2010). Because China is undergoing dramatic changes, from the perspective of economic or cultural value, the values of collectivism and interdependence self might shift towards individualism and independence self. In the changing China culture dimension, how will the transformation of individual's self-construal affect the attitude toward advertising and advertised product?

Hwang and Lee(2018) investigated the influence of self-construal on environmental values and behavior. As far as our knowledge goes, past research concerned with China have given little attention to the moderation roles of self-construal. As we mentioned before, China has not only a rapid economic development, but also makes a change in cultural value orientation. Rapidly changing society and globalization might help traditional culture and western thoughts to coexist in China(Kolstad \& Gjesvik, 2014). So it is valuable to marketers to explore the effects of advertising type and self-construal on Chinese consumers' behaviors.

It is necessary to explore the advertised product attitude difference between interdependent Chinese self-construal and independent Chinese self-construal. Therefore this study focuses on roles of self-construal type and advertising type in Chinese consumers' forming attitude toward the advertised product.

\section{Literature Review}

\subsection{Collectivism and Individualism}

Schwartz(2006) presented that measuring cultural value orientations should focus on basic values which can seem as beliefs, desirable goals, standards for social activity, action-guiding criteria which can be hierarchical feature to culture. The division of cultural value orientation is based on the most basic values which influence all aspects of society.

A large number of studies are related to cultural value orientations about individualism and collectivism(Killen \& Wainryb, 2000). Individualism and collectivism refer to that nature of the relationship between the person and the collective, and also refers to the difference between self-achieving and group goals(Bhawuk, 2001). Collectivism and Individualism are two different cultural patterns as the most powerful cultural dimension in explaining cognitive, attitudes, and behaviors. The discussion of individualism and collectivism has been presented in various contexts. For example, relevant to Triandi and Hofstede's discussion, individualism and collectivism as culture phenomenon influence both individual and society. Collectivism and Individualism are regarded as two important models to distinguish different cultures in cultural dimensions(Hofstede, 1980; Triandis, 2000). Collectivism is the belief of the traditional and less rich ethical society, while individualism has always been regarded as the belief of the rich western modern society. Collectivism culture represents the pursuit of common goals, the yearning for group harmony, and pays attention to being harmonious with others. Individualism culture pays more attention to the pursuit of individual goals and yearns for individual success and uniqueness.

Much of the past research so far has been conducted on East Asian and Western cultures to distinguish individualism from collectivism. However, individualism and collectivism can be discussed in any culture or in sole culture, because culture is diversified around the world. So it is necessary to notice that collectivism and individualism also can simultaneously coexist within an individual or a culture.

\subsection{Interdependent versus Independent self}

Different cultural backgrounds determine people's understanding of themselves, others and their relationships with others. The cultural patterns of both individualism and collectivism are linked to an important psychological phenomenon as the way by which people understand themselves. Self-construal can also be an important factor by which people judge whether they fit in the relation to others. 
Self-construal reflects the individual's view of themselves as a separate entity that can influence and determine the intrinsic nature of the individual: cognition, emotion, motivation(Markus \& Kitayama, 1991). Self-construal contains two main dimensions, that is, independent self-construal and interdependent self-construal(Singelis, 1994). Individualism and collectivism correspond different self-constructs, since the form of individualism is a kind of independent self, and the form of collectivism comes from interdependent self (Markus \& Kitayama, 1991; Singelis, 1994; Triandis, 2000; Triandis \& Gelfand, 1998).

The interdependent self is more about seeing self as a part of the group, and emphasizes on maintaining the collective internal harmony. In contrast, the independent self is mainly self-centered and focuses on the success and failure of the individual own(Markus \& Kitayama, 1994).

\subsection{Self-construals and Advertising effects}

Targeting particular audiences for Ad and product can maximize the Ad effectiveness. This paper will confirm the influence of self-construals on the Chinese consumers' attitude toward two types of $\mathrm{Ad}$, harmony-focused $\mathrm{Ad}$ and uniqueness-focused Ad. The meaning of the advertisement is to arouse consumers' attention and acceptance of the advertisement to achieve the best possible propagation effect.(Shimp, 2000). In the past research advertising message types affecting brand attitude can be shown in $<$ Table 1>. Consumer's personality traits and self-image can be used as advertising contents for a brand to be linked to his or her identities(Aaker, 1997), or who he or she is(Belk, Mayer, \& Bahn, 1982). And using consumers' identity as the message content can motivate them to express their identity by consuming the brand advertised(Escalas \& Bettman, 2005). Social identity-focused message could facilitate internal identification with their self and external identification with their society. In this sense, consumers sharing some social aspects with others may be persuaded by the social identitybased message(Shang, Croson, \& Reed, 2007). Brand attitude can be different according to whether the advertising information matches their warmth identity or competence identity(Dubois, Rucker, \& Galinsky, 2016), and whether it defines identity or references the identity(Bhattacharjee, Berger, \& Menon, 2014).

< Table 1> Past studies about advertising message

\begin{tabular}{|c|c|}
\hline Message Type & Sources \\
\hline personality traits and self-image & Aaker (1997) \\
\hline who consumer is & Belk, Mayer, \& Bahn (1982) \\
\hline consumers' identity & Escalas \& Bettman (2005) \\
\hline cultural values & Lin (2001) \\
\hline social identity-focused & Shang, Croson, \& Reed (2007) \\
\hline identity-defining or referencing & $\begin{array}{c}\text { Bhattacharjee, Berger, \& Menon } \\
(2014)\end{array}$ \\
\hline warmth identity & Dubois, Rucker, \& Galinsky \\
or competence identity & $(2016)$ \\
\hline
\end{tabular}

Ads can evoke consumers' emotion to help make a decision. In reality, when consumers are making a decision, emotion comes first, and these emotion create preferences, which can lead to our decision(Bechara \& Damasio, 2005). For example, if they get positive emotion from the Ad, which can lead to their positive attitude toward the product that is advertised.

Advertising effect is closely linked to cultural values which can define and represent the society(Lin, 2001). And advertisements should be designed in a way that can appeal to the target audience. This study compares advertisements focused on harmony with those on uniqueness from the perspectives of independent versus interdependent Chinese self-construal.

\subsubsection{Roles of Consumer Self-construal in Harmony- focused Advertising Effects}

Harmony-focused advertising is a unique way of disseminating information based on that harmony of building relationship between individual and his or her friend(Burchett, 2002; Chuang \& Ou, 2001). Harmony-focused Advertising expresses a kind of social activities, by which people make living together in the society. The social benefit of harmonyfocused advertising is based on the collective interest, which pays attention to the harmony of the collective interest and conveys the collective social responsibility of interdependent self(Cross \& Markus, 1995) which could induce links between individuals(Gorn, 1982; Greenwald \& Leavitt, 1984).

Harmony-focused advertising focuses on the information and values that are required to the harmony between individual and his or her environment. The effects of harmonious advertising reflects the development of harmony in society (Smith, 1996).

$<\mathrm{H} 1>$ Interdependent Chinese consumers' attitude toward harmony-focused advertising is more positive than independent Chinese consumers' attitude.

Advertising messages can influence product attitudes and cognition, and even purchase intentions(Black \& Wiliam, 1998). Kotler and Keller(2003) suggested that consumers' attitudes to advertising can transfer to product attitude. So if consumer with interdependent self may like the product in the harmony-focused Ad more. And the Ad can help consumers feel more about harmony. This can aid consumers better like the product which is advertised.

$<\mathrm{H} 2>$ Interdependent Chinese consumers' attitude toward the brand in harmony-focused advertising is more positive than independent Chinese consumers' attitude.

\subsubsection{Roles of self-construal in Uniqueness-focused Advertising Effects}

Uniqueness-focused advertising can evoke consumer's individual implicit emotion which can influence independent consumers' purchasing behavior(Gorn, 1982; Greenwald \& 
Leavitt, 1984).

The better the brand personality is described by advertising appeal, the more positive consumers' attitude towards the brand will be. The elaboration of series of words and pictures produced by advertisements can induce good self-implication of consumers. For example, when consumers see a confident and successful person in the advertisement who is calm and generous, can show elegant temperament without any words. It is obvious that this advertisement represents self-success and self-uniqueness. Based on such advertising positioning, its audience is mostly those with independent selves, because independent selves pay more attention to personal success and personal uniqueness (Haugtvedt, Petty, \& Cacioppo, 1992). 'Uniqueness' makes people feel different from others by highlighting the unique characteristics of advertising model(Snyder \& Fromkin, 1977). The unique advertisement infuses the individualistic emotion and the enjoyment factor, and could pass the emotion factor effectively to the target audience(Zajonc, 1980; Zajonc \& Markus, 1982). Since uniqueness-focused advertisements highlight the features of individuals, consumers are easy to associate their personality features with the products advertised (Rubinson, 2009), which will lead to positive attitude.

With the change into market economy system, Chinese consumers' status, function and value can be shown by commodity symbolic values since they could put emphasis on material benefits and individual's performance indicating his or her own achievement and success under the condition of market economy. Under the influence of China's emphasis on free competition, individuals in China could build more preference for succuss and achievement (Schwartz, 2006). Free and effective competitions in market could lead Chinese consumers to pay attention to the benefits which can help them show success and achievement more easily.

$<$ H3> Independent Chinese consumers' attitude toward uniqueness-focused advertising is more positive than interdependent Chinese consumers' attitude.

$<\mathrm{H} 4>$ Independent Chinese consumers' attitude toward the brand in uniqueness-focused advertising is more positive than interdependent Chinese consumers' attitude.

All the hypotheses are summarized in <Figure $1>$.

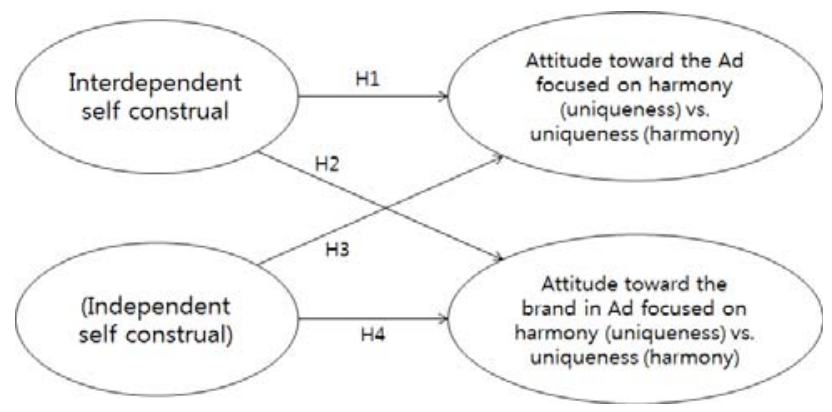

<Figure 1> Research hypotheses

\section{Methodology and Data Collection}

\subsection{Experimental Object and Advertisement Development}

Our study uses mobile phone as an experimental object since almost everyone has it. Two types of picture advertisement(harmony and uniqueness) were developed and anonymous brand ' $\mathrm{K}$ ' was used as mobile phone brand name to avoid the effects of brand fame on brand attitude.

\subsubsection{Harmony-focused Ad development}

This study developed two harmony-focused Ads showing a group of friends being harmonious with each other through ' $\mathrm{K}$ ' mobile phone. In the two Ads which are pictured sequentially in questionnaire, the friends are laughing and harmonious with each other and enjoy a good time. Also there is a slogan 'enjoy harmony between you and your friends by ' $K$ ' mobile phone.'

\subsubsection{Uniqueness-focused Ad development}

We also developed two uniqueness-focused Ads showing a successful man enjoying ' $k$ ' mobile phone which are pictured sequentially in questionnaire. In the Ads the model man looks confident with success and makes smile. Also a slogan 'enjoy your own success by ' $\mathrm{K}$ ' mobile phone' there is in the Ads.

\subsection{Measures}

\subsubsection{Measures of Interdependence and Independence}

For the purpose of measuring the consumers' self-construal that means how they think themselves and relationship with others. We use 24 scales from Singelis (1994). And the first 12 items are about interdependent property and the last 12 items are of independent property. Consumers' self-construal is calculated by subtracting the sum of first 12 items' score from the sum of last 12 items' score which makes dummy variable based on zero.

\subsubsection{Brand attitude measurements}

To measure the attitude toward ' $\mathrm{K}$ ' mobile phone, 4 items (Roehm \& Sternthal, 2001) were chosen and modified. 'The "K" mobile phone is useful,' 'The " $K$ " mobile phone is practical,' 'The "K" mobile phone is valuable to me,' 'The " $\mathrm{K}$ " mobile phone is advanced to me,' was used on 7-point scale (1=strongly disagree, $7=$ strongly agree).

\subsubsection{Ad Attitude Measurements}

To measure attitude toward the Ads we used 3 items: 'The advertisement was informative,' 'The advertisement was easy-to-follow,' 'The advertisement was clear' on 7 point scale (1=strongly disagree, $7=$ =strongly agree), based on Homer(1995). 


\subsection{Data}

We conducted main survey online with the people in China, and collected 116 data by using harmony $\mathrm{Ad}$ questionnaire and 120 data by using uniqueness $\mathrm{Ad}$ questionnaire. In order to distinguish between the two kinds of self-construal, we subtracted the sum of first 12 items' score from the sum of last 12 items' score and divide it by 12. Those scores above zero are the interdependent self and those scores below zero are independent self. The 9 participants with the score of zero were deleted.

The demographic variables included age, gender, salary and nationality. As a result, $44.5 \%$ of the participants were male and $57.9 \%$ of them were aged $20-30$ years old.

\section{Basic Analysis and Testing Hypotheses}

\subsection{Reliability and Validity}

Principal component analysis based on Varimax in SPSS 21.0 program was conducted to check convergent validity of the items for each construct at each type of Ad data.

The analysis results of <Table 2> showed that there were two components in each data respectively. And in harmonyfocused Ad, brand attitude $(\alpha=.905)$ and Ad attitude $(\alpha=.849)$ there were. In uniqueness-focused Ad there were Brand attitude $(\alpha=.740)$, and $\operatorname{Ad}$ attitude $(\alpha=.678)$. The reliability and the convergent validity were verified. Summed and averaged score for each of brand attitude and Ad attitude is used.

<Table 2> Results of Analyzing Components

\begin{tabular}{|c|c|c|c|c|c|}
\hline & \multirow{2}{*}{ Construct } & \multirow{2}{*}{ Item } & \multicolumn{2}{|c|}{ Component } & \multirow{2}{*}{$\alpha$} \\
\hline & & & 1 & 2 & \\
\hline \multirow{7}{*}{$\begin{array}{l}\text { Harmony } \\
\text {-focused } \\
\text { Ad }\end{array}$} & \multirow{2}{*}{ Brand } & phoneatt 3 & .860 & .291 & \multirow{4}{*}{.905} \\
\hline & & phoneatt 4 & .843 & .262 & \\
\hline & \multirow{2}{*}{ attitude } & phoneatt 2 & .798 & .449 & \\
\hline & & phoneatt 1 & .798 & .232 & \\
\hline & \multirow{3}{*}{$\begin{array}{c}\text { Ad } \\
\text { attitude }\end{array}$} & adattitude 2 & .189 & .897 & \multirow{3}{*}{.849} \\
\hline & & adattitude 3 & .343 & .826 & \\
\hline & & adattitude 1 & .385 & .735 & \\
\hline \multirow{7}{*}{$\begin{array}{c}\text { Uniqueness } \\
\text {-focused } \\
\text { Ad }\end{array}$} & \multirow{4}{*}{ Brand } & phoneatt 2 & .825 & .107 & \multirow{4}{*}{.740} \\
\hline & & phoneatt 1 & .709 & .162 & \\
\hline & & phoneatt 3 & .695 & .158 & \\
\hline & & phoneatt 4 & .676 & .278 & \\
\hline & \multirow{3}{*}{$\begin{array}{c}\text { Ad } \\
\text { attitude }\end{array}$} & ad attitude 1 & .148 & .808 & \multirow{3}{*}{.678} \\
\hline & & ad attitude 2 & .123 & .769 & \\
\hline & & ad attitude 3 & .281 & .695 & \\
\hline
\end{tabular}

\subsection{Testing Hypotheses}

\subsubsection{Testing Hypotheses concerned with harmony-focused Ad}

To verify whether self-construal can influence harmony- focused Ad and attitude to the brand in the Ad, t-test was conducted.

The attitude toward harmony-focused $\mathrm{Ad}(\mathrm{Minter}=5.284)$ was more positive to the interdependent consumers than to the independent consumers(Mindepen=3.970) as shown in $<$ Table 3>. <H1 > was supported.

$<$ Table 3> Results of t-test related to harmony-focused Ad Attitude

\begin{tabular}{|c|c|c|c|c|c|c|}
\hline & Self & N & Mean & df & t-value & p \\
\hline \multirow{2}{*}{$\begin{array}{c}\mathrm{Ad} \\
\text { attitude }\end{array}$} & interdependent & 62 & 5.284 & & & \\
\cline { 2 - 7 } & independent & 45 & 3.970 & 6.092 & .000 \\
\hline
\end{tabular}

To verify $<\mathrm{H} 2>$, Anova with Ad attitude as covariate was conducted, the results of which are shown in <Table $4>$ and $<$ Table 5>. We found that in harmony-focused advertising, interdependent consumers(Minter=4.818) show more positive attitude towards the brand advertised rather than independent consumers(Mindepen=3.194). And this difference was significant( $F 1,104=44.394, p<.01)$. Also Ad attitude as a covariate played a significant role. So $<\mathrm{H} 2>$ was supported.

$<$ Table 4> Descriptive attitude statistics for the brand in harmonyfocused Ad

\begin{tabular}{|c|c|c|c|}
\hline Self & Mean & SD & N \\
\hline interdependent & 4.818 & .85191 & 62 \\
\hline independent & 3.194 & .84761 & 45 \\
\hline Total & 4.135 & 1.16821 & 107 \\
\hline
\end{tabular}

<Table 5> Anova results for brand attitude in harmony-focused advertising

\begin{tabular}{|c|c|c|c|c|c|c|}
\hline Source & $\begin{array}{l}\text { Type III } \\
\text { Sum of } \\
\text { Squares }\end{array}$ & df & $\begin{array}{c}\text { Mean } \\
\text { Square }\end{array}$ & $F$ & Sig. & $\begin{array}{l}\text { Partial Eta } \\
\text { Squared }\end{array}$ \\
\hline Corrected Model & $86.203^{a}$ & 2 & 43.101 & 76.681 & .000 & .596 \\
\hline Intercept & 29.676 & 1 & 29.676 & 52.797 & .000 & .337 \\
\hline Ad attitude & 17.452 & 1 & 17.425 & 31.001 & .000 & .230 \\
\hline self-construal & 24.953 & 1 & 24.953 & 44.394 & .000 & .299 \\
\hline Error & 58.457 & 104 & .562 & & & \\
\hline Total & 1974.625 & 107 & & & & \\
\hline Corrected Total & 144.660 & 106 & & & & \\
\hline
\end{tabular}

a. $\mathrm{R}$ Squared $=.596$ (Adjusted R Squared $=.588$ )

\subsubsection{Testing Hypotheses concerned with uniqueness- focused Ad}

A t-test was also conducted to test the influence of self-construal on uniqueness-focused $\mathrm{Ad}$ and attitude to the brand advertised in the uniqueness-focused Ad. The result was shown in <Table 6>. We found out there was no significant difference between the two type self $(t=.058$, $p>$.05). So $<H 3>$ was rejected. 
$<$ Table $6>$ Results of t-test related to uniqueness-focused Ad Attitude

\begin{tabular}{|c|c|c|c|c|c|c|}
\hline & Self & $\mathbf{N}$ & Mean & df & t-value & $\mathbf{p}$ \\
\hline \multirow{2}{*}{ Ad attitude } & interdependent & 56 & 5.226 & \multirow{2}{*}{107} & \multirow{2}{*}{.058} & \multirow{2}{*}{.954} \\
\cline { 2 - 7 } & independent & 53 & 5.214 & & & \\
\hline
\end{tabular}

To verify $<\mathrm{H} 4>$, Anova with Ad attitude as covariate was conducted, the results of which are shown in $<$ Table $7>$ and $<$ Table 8>. In uniqueness-focused advertising, independent consumers(Mindepen=5.033) showed more positive attitude towards the brand rather than interdependent consumers (Minter=4.406). The difference was significant( $F 1,106=12.733$, $\mathrm{p}<.01$ ). Also Ad attitude as a covariate played a significant role. So $<\mathrm{H} 4>$ was supported.

$<$ Table 7> Descriptive attitude statistics for the brand in uniquenessfocused Ad

\begin{tabular}{|c|c|c|c|}
\hline Self & Mean & SD & N \\
\hline interdependent & 4.406 & 1.00743 & 56 \\
\hline independent & 5.033 & 1.07421 & 53 \\
\hline Total & 4.711 & 1.08236 & 109 \\
\hline
\end{tabular}

<Table 8> Anova results for brand attitude in uniqueness-focused advertising

\begin{tabular}{|c|c|c|c|c|c|c|}
\hline Source & \begin{tabular}{|l|} 
Type III \\
Sum of \\
Squares
\end{tabular} & df & $\begin{array}{l}\text { Mean } \\
\text { Square }\end{array}$ & F & Sig. & $\begin{array}{l}\text { Partial Eta } \\
\text { Squared }\end{array}$ \\
\hline Corrected Model & $35.950^{\mathrm{a}}$ & 2 & 17.975 & 21.037 & .000 & .284 \\
\hline Intercept & 28.431 & 1 & 28.431 & 33.274 & .000 & .239 \\
\hline Ad attitude & 25.254 & 1 & 25.254 & 29.556 & .000 & .218 \\
\hline Self & 10.880 & 1 & 10.880 & 12.733 & .001 & .107 \\
\hline Error & 90.571 & 106 & .854 & & & \\
\hline Total & 2545.625 & 109 & & & & \\
\hline Corrected Total & 126.522 & 108 & & & & \\
\hline
\end{tabular}

a. $\mathrm{R}$ Squared $=.284$ (Adjusted R Squared $=.271$ )

\subsubsection{Testing Ad and Brand attitude Differences between Ad Types at Each Self Construal}

<Table 9> Anova results for $\mathrm{Ad}$ and brand attitude at each self-construal

\begin{tabular}{|c|c|c|c|c|}
\hline Self & \multicolumn{2}{|c|}{ Ad attitude } & \multicolumn{2}{c|}{ Brand attitude } \\
\hline \multirow{4}{*}{ interdependent } & harmony-focused & 5.284 & harmony-focused & 4.818 \\
\cline { 2 - 5 } & uniqueness-focused & 5.226 & uniqueness-focused & 4.406 \\
\cline { 2 - 5 } & $\mathrm{F} 1,116=.088, P>.05$ & $\mathrm{~F} 1,116=5.797, \mathrm{P}<.05$ \\
\hline \multirow{4}{*}{ independent } & harmony-focused & 3.970 & harmony-focused & 3.194 \\
\cline { 2 - 5 } & uniqueness-focused & 5.214 & uniqueness-focused & 5.033 \\
\cline { 2 - 6 } & \multicolumn{2}{|c|}{$\mathrm{F} 1,96=28.226, \mathrm{P}<.01$} & $\mathrm{~F} 1,96=86.204, \mathrm{P}<.01$ \\
\hline
\end{tabular}

In addition, Anova was conducted to explore the Ad and brand attitude differences between Ad types at each self-construal. As shown in <Table 9>, Chinese consumers under independent self-construal formed higher attitude toward both of the $\operatorname{Ad}(\mathrm{F} 1,96=28.226, p<.01)$ and the brand $(F 1,96=86.204, p<.01)$ advertised by focusing on uniqueness rather than by focusing on harmony. However consumers under interdependent self-construal formed higher attitude toward the brand(F1,116=5.797, $p<.05)$ advertised by focusing on harmony rather than by focusing on uniqueness, but they did not Ad attitude difference between the $\mathrm{Ad}$ types(F1,116=.088, p>.05).

\section{General Discussion}

\subsection{Research Summary}

We investigated the value change in china through reviewing past research, and gave attention to the influence of self-construal on the two types of $\mathrm{Ad}$ and attitude toward the brand in each Ad.

The results are as follows.

First, interdependent Chinese consumers showed more positive attitude towards harmony-focused $\mathrm{Ad}$ and the brand in it than independent Chinese consumers.

Second, there was no attitude difference towards uniqueness-focused Ad between the independent Chinese consumers and the interdependent Chinese consumers. However the independent Chinese consumers show more positive attitude towards the brand in the uniqueness-focused Ad than the interdependent Chinese consumers.

Additionally while interdependent Chinese consumers formed higher attitude toward the brand in the advertisement focused on harmony rather than uniqueness, independent Chinese consumers built higher attitude toward the brand in the advertisement emphasizing uniqueness rather than harmony.

\subsection{Theoretical and Managerial Implication}

According to the findings of our study, there are some theoretical and practical implications.

Current research pointed out that there are brand attitude differences between the interdependent Chinese consumers and the independent Chinese consumers when the brand is advertised by focusing on harmony as well as uniqueness. And this research explores there was no significant attitude difference between the self constural types towards the uniqueness-focused Ad. That means both independent Chinese consumers and interdependent Chinese consumers equally like the uniqueness-focused $\mathrm{Ad}$. As we have presented, China is undergoing great changes into market economic system, and with this changes Chinese people can be affected at all aspects of the society. They may also change their individual value. Even interdependent Chinese consumers with their dominant ideology is pursuing harmony, they can be also appealed by the uniqueness-focused Ad. And from the result of verifying $\langle\mathrm{H} 4\rangle$, we found that with 
positive attitude to the uniqueness-focused Ad, independent Chinese consumers showed more positive attitude towards the brand in the uniqueness-focused Ad. Therefore the results of this research can contribute to the development of consumer theory concerned with Chinese people.

This paper can provide some suggestions for the marketers targeting China market. They should do a good job in segmenting China market to make clear the target market and promoting their brands or products by taking the self-construal difference into account. It is necessary for them to highlight the attributes of Chinese consumers' self-construal. They should develop harmony-focused advertisement to appeal to interdependent Chinese consumers and do uniqueness-focused advertisement to appeal to independent Chinese consumers.

However the dominant ideology of Chinese people might be harmony rather than uniqueness. Interdependent Chinese consumers did not show Ad attitude difference between the uniqueness-focused $\mathrm{Ad}$ and the harmony-focused $\mathrm{Ad}$. Although some Chinese people have been reversed to enjoying their own uniqueness, Chinese people pursue harmony as the main content in the overall environment, uniqueness might be just supplemented to them. Therefore the marketers should consider the harmony even when they appeal Chinese consumers by emphasizing the uniqueness.

\subsection{Limitations and Future Research}

There are also some limitations that should be explained by future study.

First, actually people may not always act according to their cultural values. In other words, cultural values do not always predict individual behavior. And also from the perspective of Kiuchi(1995) focused on personality and individual difference in proposing a model of interdependent and independent self, each individual possesses both independent and interdependent aspects of the self. The relative priority of these aspects determines differences related to the individual's social behavior. Therefore it is necessary to consider the cues by which any one of the construals could be activated in future research.

Second, individuals under individualism culture may sense personal power to escape from a unit with others, whereas those under collectivism culture may sense belongingness to their social relations to build the relationship with others(Choi \& Dhakal, 2017; Choi, Park, \& Lim, 2018). Therefore there is a possibility that interdependent (independent) Chinese consumers might (not) accept the self defined by their ingroup. Future research could be approached in view of the self defined by others.

Despite its limitation, we thought it is really important and a good idea to pay attention to different cultural value in one group or one country, because culture itself is pluralistic especially in today's globalization.

\section{References}

Aaker, J. (1997). Dimensions of brand personality. Journal of Marketing Research, 34(3), 347-357.

Bechara, A., \& Damasio, A. R. (2005). The somatic marker hypothesis: A neural theory of economic decision. Games and Economic Behavior, 52(2), 336-372.

Belk, R. W., Mayer, R., \& Bahn, K. (1982). Developmental recognition of consumption symbolism. Journal of Consumer Research, 9(1), 4-17.

Bhattacharjee, A., Berger, J., \& Menon, G. (2014). When Identity Marketing Backfires: Consumer Agency in Identity Expression. Journal of Consumer Research, 41(2), 294-309.

Bhawuk, D. P. (2001), Evolution of culture assimilators: Toward theory-based assimilators, International Journal of Intercultural Relations, 25(2), 141-163.

Black, P., \& Wiliam, D. (1998). Assessment and classroom learning. Assessment in Education: Principles, Policy \& Practice, 5(1), 7-74.

Burchett, K. E. (2002). Color harmony. Color Research \& Application, 27(1), 28-31.

Choi, N.-H.. Park. S.-M., \& Lim, A.-Y. (2018). Roles of consumer's social relationship and perceived justice type on service recovery satisfaction. International Journal of Industrial Distribution \& Business, 9(1), 77-88.

Choi, N.-H., \& Dhakal, A. (2017). Roles of power state and message types on restaurant store brand attitude. Journal of Distribution Science, 15(10), 5-14.

Chuang, M. C., \& Ou, L. C. (2001). Influence of a holistic color interval on color harmony. Color Research \& Application, 26(1), 29-39.

$\mathrm{Ci}$, J. (1994). Dialectic of the Chinese Revolution: From Utopianism to Hedonism. Stanford University Press.

Cross, S. E., \& Markus, H. R. (1995). Self-construal, coping, and stress in cross-cultural adaptation. Journal of Cross-Cultural Psychology, 26(6), 673-697.

Dubois, D., Rucker, D. D., \& Galinsky, A. D. (2016). Dynamics of communicator and audience power: The persuasiveness of competence versus warmth. Journal of Consumer Research, 43(1), 68-85.

Emery, C., \& Tian, K. R. (2010). China compared with the US: Cultural differences and the impacts on advertising appeals. International Journal of China Marketing, 1(1), 45.

Escalas, J. E., \& Bettman, J. R. (2005). Self-construal, reference groups, and brand meaning. Journal of Consumer Research, 32(3), 378-389. 
Gorn, G. J. (1982). The effects of music in advertising on choice behavior: A classical conditioning approach. Journal of Marketing, 46(1), 94-101.

Greenwald, A. G., \& Leavitt, C. (1984). Audience involvement in advertising: Four levels. Journal of Consumer research, 11(1), 581-592.

Haugtvedt, C. P., Petty, R. E., \& Cacioppo, J. T. (1992). Need for cognition and advertising: Understanding the role of personality variables in consumer behavior. Journal of Consumer Psychology, 1(3), 239-260.

Ho, D. Y.-F., \& Chiu, C.-Y. (1994). Component ideas of individualism, collectivism, and social organization: An application in the study of Chinese culture. In U. Kim, H. C. Triandis, Ç. Kâğitçibași, S.-C. Choi, \& G. Yoon (Eds.), Cross-cultural research and methodology series, Vol. 18. Individualism and collectivism: Theory, Method, and Applications (pp. 137-156). Thousand Oaks, CA, US: Sage Publications.

Hofstede, G. (1980). Motivation, leadership, and organization: Do American theories apply abroad?. Organizational Dynamics, 9(1), 42-63.

Homer, P. M. (1995). Ad size as an indicator of perceived advertising costs and effort: The effects on memory and perceptions. Journal of Advertising, 24(4), 1-12.

Hwang, K., \& Lee, J. (2018). Antecedents and consequences of ecotourism behavior: Independent and interdependent self-Construals, ecological Belief, willingness to pay for ecotourism services and satisfaction with life. Sustainability, 10(3), 789.

Killen, M., \& Wainryb, C. (2000). Independence and interdependence in diverse cultural contexts. New Directions for Child and Adolescent Development, 87, 5-21.

Kim, U. (1994). Individualism and collectivism: Conceptual clarification and elaboration. Cross Cultural Research and Methodology Series-Sage, 18(1), $19-40$.

Kiuchi, A. (1995). Construction of a scale for independent and interdependent construal of the self and its reliability and validity. Japanese Journal of Psychology, 66(2), 100-106.

Kolstad, A., \& Gjesvik, N. (2014). Collectivism, individualism, and pragmatism in China: Implications for perceptions of mental health. Transcultural Psychiatry, 51(2), 264-285.

Kotler, P., \& Keller, K. L. (2003). Marketing Management: International Edition. New Jersey: Prentice Hall.

Lee, J. W., \& Wang, Z. (2018). Spillover effects of foreign direct investment inflows and exchange rates on the banking industry in China. Journal of
Asian Finance, Economics and Business, 5(2), 15-24.

Lin, C. A. (2001). Cultural values reflected in Chinese and American television advertising. Journal of Advertising, 30(4), 83-94.

Markus, H. R., \& Kitayama, S. (1991). Culture and the self: Implications for cognition, emotion, and motivation. Psychological Review, 98(2), 224-253.

Markus, H. R., \& Kitayama, S. (1994). A collective fear of the collective: Implications for selves and theories of selves. Personality and Social Psychology Bulletin, 20(5), 568-579.

Morrison, W. M. (2014). China's economic rise: History, trends, challenges, and implications for the United States. Current Politics and Economics of Northern and Western Asia, 23(4), 493.

Roehm, M. L., \& Sternthal, B. (2001). The moderating effect of knowledge and resources on the persuasive impact of analogies. Journal of Consumer Research, 28(2), 257-272.

Rubinson, J. (2009). Empirical evidence of TV advertising effectiveness. Journal of Advertising Research, 49(2), 220-226.

Schwartz, S. H. (2006). A theory of cultural value orientations: Explication and applications. Comparative Sociology, 5(2), 137-182.

Shang, J., Croson, R., \& Reed, A. (2007). "l" Give, but "We" Give More: The Impact of identity and the mere social information effect on donation behavior. NA-Advances in Consumer Research, 34, 421-428.

Shimp, T. A. (2000). Advertising Promotion: Supplemental Aspects of Integrated Marketing Communications. London: Harcourt Brace.

Singelis, T. M. (1994). The measurement of independent and interdependent self-construals. Personality and Social Psychology Bulletin, 20(5), 580-591.

Singh, P. N., Huang, S. C., \& Thompson, G. G. (1962). A comparative study of selected attitudes, values, and personality characteristics of American, Chinese, and Indian students. Journal of Social Psychology, 57(1), 123-132.

Smith, E. R. (1996). What do connectionism and social psychology offer each other?. Journal of Personality and Social Psychology, 70(5), 893.

Snyder, C. R., \& Fromkin, H. L. (1977). Abnormality as a positive characteristic: The development and validation of a scale measuring need for uniqueness. Journal of Abnormal Psychology, 86(5), 518-527.

Triandis, H. C. (2000). Culture and conflict. International Journal of Psychology, 35(2), 145-152. 
Triandis, H. C., \& Gelfand, M. J. (1998). Converging measurement of horizontal and vertical individualism and collectivism. Journal of Personality and Social Psychology, 74(1), 118-128.

Yang, K. S. (1981). Social orientation and individual modernity among Chinese students in Taiwan. Journal of Social Psychology, 113(2), 159-170.

Zajonc, R. B. (1980). Feeling and thinking: Preferences need no inferences. American Psychologist, 35(2),
151-175.

Zajonc, R. B., \& Markus, H. (1982). Affective and cognitive factors in preferences. Journal of Consumer Research, 9(2), 123-131.

Zhao, X., \& Belk, R. W. (2008). Politicizing consumer culture: Advertising's appropriation of political ideology in China's social transition. Journal of Consumer Research, 35(2), 231-244. 